\title{
Air Quality Enhancement Districts: democratizing data to improve respiratory health
}

\author{
Kelly A. Stevens ${ }^{1}$ (D) Thomas A. Bryer ${ }^{1}$ (D) Haofei $\mathrm{Yu}^{2}$ (D)
}

Accepted: 28 January 2021 / Published online: 4 February 2021

(C) AESS 2021

\begin{abstract}
The U.S. Centers for Disease Control and Prevention has recently acknowledged that the principal mode for SARSCoV-2 (the virus that causes COVID-19) to spread is through airborne particles. Reducing levels of particulate matter, a form of air pollutant, may decrease the spread of the virus and save lives. In this article, we propose establishing local Air Quality Enhancement Districts using low-cost air quality sensors. Air quality sensors provide more detailed data on particulate matter concentrations than what is currently provided by the U.S. Environmental Protection Agency, which will allow communities and individuals to make better informed decisions about activities during poor air quality days. The core principles behind local Air Quality Enhancement Districts is to (1) provide citizens with more localized data on air quality, (2) raise awareness on localized pollution and health impacts related to COVID-19, and (3) empower citizens and local governments to take quick actions to reduce exposure and respiratory distress during times of poor air quality.
\end{abstract}

Keywords COVID-19 $\cdot$ Air quality $\cdot$ Citizen science

On October 5, 2020, The U.S. Centers for Disease Control and Prevention (U.S. CDC) has officially acknowledged that the principal mode for SARS-CoV-2 (the virus that causes COVID-19) to spread is through airborne particulate matter (droplet and particles) (U.S. CDC 2020). Preliminary research on COVID-19 (e.g., Comunian et al. 2020; Liu et al. 2020; Mehmood et al. 2020; Wu et al. 2020) has also found that patients in areas with higher levels of fine air particulates, known as $\mathrm{PM}_{2.5}$, are more likely to die from a COVID-19 infection than patients in areas with cleaner air quality. The COVID-19 virus causes respiratory illnesses that can lead to acute respiratory distress syndrome, which in some cases requires a ventilator for survival, and may cause permanent lung damage (Cox 2020). Therefore, it is possible that COVID-19 will result in an increased number of individuals who are sensitive to

Kelly A. Stevens

Kelly.Stevens@ucf.edu

1 University of Central Florida, School of Public Administration, Orlando, FL, USA

2 Department of Civil, Environmental, and Construction Engineering, University of Central Florida, Orlando, FL, USA poor air quality. Though the Trump administration engineered drastic rollbacks of environmental regulations, even in the midst of the COVID-19 pandemic, future steps may be needed to (1) equip individuals with better information about local air quality on poor air quality days, and (2) empower communities to modify activities and advocate air quality concerns in the short and long term to reduce exposure to air pollution.

In this article, we use a multi-disciplinary approach, drawing from the fields of environmental health and engineering, as well as public administration and policy, to explain the link between COVID-19 and air quality and to propose a community-engaged solution. We propose specific ways in which low-cost air quality sensors and local air quality enhancement districts can improve our current regulatory structure and tools to protect public health during the pandemic and afterwards. We hope this information leads to collaborative deployment of sensors and networks in areas hardest hit by COVID-19 that are also more commonly exposed to poor air quality, including environmental justice communities. Following models from parallel structures, we describe the technology and management design to quickly implement air quality protective actions, and possibly save lives. 


\section{Air quality and COVID-19}

\section{Link between air quality and COVID-19}

$\mathrm{PM}_{2.5}$ refers to particulate matter with aerodynamic diameter equal or less than 2.5 micrometers, consisting of a complex mixture of both solid and liquid droplets suspended in the air. Tiny particles of these sizes are more likely to penetrate deep inside lungs and have the potential to cause significant adverse health effects, including difficulty breathing, heart-attacks, aggravated asthma, decreased lung function, and premature death (Wu et al. 2020; Wang et al. 2020). In 2015 alone, exposure to $\mathrm{PM}_{2.5}$ is believed responsible for approximately 8.9 million premature deaths worldwide, with 213,000 premature deaths in the USA and Canada alone (Burnett et al. 2018).

$\mathrm{PM}_{2.5}$ is a complex pollutant because it can come in many different sizes and shapes, and can consist of hundreds of chemical species. Some of the $\mathrm{PM}_{2.5}$ components can be attributed to direct emissions (such as construction and road dusts, power plants, biomass burning and motor-vehicles), while others may be formed through chemical reactions occurring in the air. The toxicity of $\mathrm{PM}_{2.5}$ can also vary depending on its chemical composition, with vehicle exhausts and fire emissions found to be more harmful than others (Park et al. 2018). While the underlying biological mechanism on how $\mathrm{PM}_{2.5}$ adversely impacts heath is still a topic of investigation, $\mathrm{PM}_{2.5}$ can trigger acute respiratory inflammation, damage human airways and weaken immune response, all of which may facilitate viral infections (Comunian et al. 2020; Lodovici and Bigagli 2011; Mehmood et al. 2020).

Recently, an increasing amount of research has suggested a statistical link between death or serious illness from COVID19 in areas with higher levels of outdoor $\mathrm{PM}_{2.5}$ concentrations (Comunian et al. 2020; Conticini et al. 2020; Fattorini and Regoli 2020; Mehmood et al. 2020; Wu et al. 2020; Yao et al. 2020; Zhu et al. 2020; Zoran et al. 2020). Similar findings were reported during the SARS outbreak, which was also caused by a coronavirus. Cui et al. (2003) found that SARS patients from highly polluted regions in China were twice as likely to die from SARS compared with patients from relatively clean regions. In the USA, race and socio-economic status are highly correlated with exposure to harmful air pollution. Already, it is being reported that African Americans are more likely to die from COVID-19, with disproportionately higher death rates in the USA (Holmes et al. 2020), and states like Illinois, Louisiana, Michigan, and Florida (Wolfe 2020; Santich 2020). While there are numerous factors that contribute to this, such as access to healthcare and higher rates of front-line and service-industry jobs, many African Americans live in urban areas with poorer air quality. Studies show African Americans have higher rates of asthma, lung, and heart disease (Miranda et al. 2011), which are associated with higher death rates from COVID-19 (Wu et al. 2020).

\section{Air quality and regulations in the USA}

Air quality in the USA continues to improve across the country, with significantly fewer areas designated as out of compliance with current ambient air quality standards. While there is much debate about how well these standards reflect the current state of science to protect public health (Heikkinen 2018; Wang et al. 2020; Parker 2016), there has been a steady improvement in air quality for most pollutants across the country, including $\mathrm{PM}_{2.5}$ (U.S. EPA 2019).

The Air Quality Index (AQI) is an index for reporting daily air quality based on federally approved air quality monitors, with a focus on health impacts (U.S. EPA 2020). The AQI identifies different air quality categories with related health impacts, ranging from "good" with no health impacts expected to "very unhealthy" which recommends limiting or completely avoiding all outdoor activities based on health sensitivity. In 2019 , approximately $26 \%$ of counties with a regulatory air quality monitor experienced at least one day where air quality was unhealthy for sensitive groups including people with heart or lung disease, older adults, and children.

Due to COVID-19's long-lasting impact on lungs and respiratory health (Cox 2020), the size of this sensitive group may grow considerably, particularly in areas hardest hit by COVID-19. Since many of these areas are already predisposed to lower air quality, this situation exacerbates the need for quick responses to poor air quality days. These areas are scattered throughout the USA, but are commonly located in high population corridors, such as the New York CityPhiladelphia-Washington, DC area, and cities such as Atlanta, Houston, and Denver.

Notably, air quality has improved in most parts of the country since stay-at-home orders have been put in place. There have been significant decreases in $\mathrm{PM}_{2.5}$ and ozone, two of the main pollutants that affect human health, since mid-March, by as much as $30 \%$ in some areas such as the West Coast before the 2020 wildfires (Freedman and Tierney 2020). The drastic improvement in air quality most likely stems from reduced vehicular travel, but more research needs to be done to measure this impact while controlling for other factors such as changes in the weather. The implication, though, is that governments can put into place localized restrictions or recommend residents stay-at-home to reduce the impact of a dangerous air quality forecast for hardest hit COVID-19 areas with a high at-risk population for respiratory distress.

Despite these improvements, the Trump Administration rolled back over 95 environmental regulations from 2017 2020 , many of these directly or indirectly affecting air quality (Popovich et al. 2019). In March and April 2020, during the COVID-19 pandemic, the U.S. EPA rolled back vehicle emissions standards that directly impact $\mathrm{PM}_{2.5}$, and announced plans to leave the current National Ambient Air Quality Standard for $\mathrm{PM}_{2.5}$ at the 2012 threshold after scientists 
recommended tightening it to be more reflective of the current state of knowledge regarding $\mathrm{PM}_{2.5}$ impact on human health (Reilly 2020; Heikkinen 2018). Studies show increased risk of premature death from fine particle pollution at levels much lower than the current $\mathrm{PM}_{2.5}$ standards, and conclude that there is no threshold level without health risks (Wang et al. 2020).

As has been the case in other elements of COVID-19 response, state and local agencies play an important role in protecting and prioritizing public health, especially when the federal response is slow and poorly coordinated. If the trends in relaxing federal air quality regulations continue, more localized networks better attuned to community needs will be needed to improve local air quality. For example, using the same reduction in death rates and $\mathrm{PM}_{2.5}$ concentration data from the Harvard study ( $\mathrm{Wu}$ et al. 2020), we find that a 1 microgram per cubic meter reduction in long-term $\mathrm{PM}_{2.5}$ averaged over 2000-2016 in New York City (approximately 8\% reduction in $\mathrm{PM}_{2.5}$ concentrations) could have saved 1915 lives that were lost to COVID-19 as of October 20, 2020 (NYSDH 2020). This could bring the death rate from COVID-19 cases down from the current rate of $9.2 \%$ to $8.4 \%$ in New York City.

\section{Recommendations}

To achieve the kinds of $\mathrm{PM}_{2.5}$ reductions described in the previous section that could have saved approximately 2,000 or more lives in New York City, and that can save lives in the event of future respiratory infections, we recommend a monumental, but not unprecedented, governance innovation. Specifically, we recommend the creation of federally funded Air Quality Enhancement Districts (AQED) in high-risk neighborhoods and communities throughout the United States. In this section, we outline the model of AQEDs, including parallel structures designed for other policy aims. We also outline the specific technologies-low-cost air quality sensors-required to implement AQEDs successfully.

\section{Core principles and outcomes AQEDs}

Three core principles and outcomes guide the enactment of AQEDs. These are both principles and outcomes simultaneously, in that they are the foundation of a transformed local governance regime and the results that can occur so long as commitment to the same principles is not corrupted or manipulated by local political or commercial interests.

The first principle is democratization of air quality data and empowerment of residents to use the data. A phrase that captures the essence of this idea emerged during the apartheid years in South Africa and has more recently been adopted for use by anti-poverty campaigners in parts of England (Bryer and Prysmakova-Rivera 2018): Nothing without us about us is for us. The meaning of this phrase is at once simple and complex. It is complex in that it raises a host of issues, such as the meaning and enactment of democratic accountability, representation, and empowerment.

Applied to air quality and the notion of AQEDs, the logic is the same. Scientific and regulatory experts can use their scientifically engineered instruments to assess air quality at given places and times, make a judgement if the assessed air quality is safe for various levels of activity based on further scientific and medical judgement, and communicate to a passive citizenry with recommendations for a range of daily activities, such as opening home windows, running the air conditioner, or exercising outdoors.

The approach suggested by the phrase - nothing without us about us is for us - challenges core assumptions of the expert model. For example, consider these scenarios:

- Residents in a neighborhood enjoy coming together for a community cookout in the local park. The City or local construction firms under contract plan infrastructure improvements that will cause an increase in air pollution. Citizens, aware of the coming spike in pollutants, work with City officials to schedule these at times not important for the neighborhood.

- Residents in a neighborhood have access to local air quality data every day, and they learn, over time, the changes in air quality that come with different weather conditions. They have more ability to plan events and activities for themselves, their families, and with their neighbors.

- Residents detect prolonged periods of higher than normal air pollution. They have access to the data they need to share with each other and with government officials to determine the source and mitigate the pollution in the short and long term.

In short, nothing without residents, particularly in urban environments, about the air breathed by residents, is done for the residents themselves. Policy actions might be taken based on scientific data, but the actions might be slow in coming and non-responsive to actual resident and neighborhood needs and interests. The underlying philosophy of this first principle is consistent with those values expressed by Agyeman (2005) in his book, Sustainable Communities and Challenges of Environmental Justice. Agyeman introduces both deliberative and inclusionary processes and procedures (DIPS) and community-based social marketing (CBSM) as means to ownership of environmental health to community members.

The second principle is resident awareness of pollution within their neighborhoods, and vulnerability to disease. Through access to data and the ability to use data on air quality, residents can further, in this model, increase their 
knowledge of how pollution leads to higher risk for other health issues, with particular concern for respiratory ailments. Education of residents is further fodder that can instigate citizen action once they are properly armed with data (Conrad and Hilchey 2011; Riesch and Potter 2014).

The continuous involvement of residents through education and data collection, and ultimately to the third element stated next, are fundamentally the ingredients of participatory action research and engaged scholarship. These principles are consistent with the tenets of the Johns Hopkins Urban Health Institution communitybased participatory research model (Agyeman 2005) and specifically are grounded in the assumption that particularly low-income, less educated residents that predominate environmental justice communities are more likely to be disempowered and manipulated through standard governance practices. Empowerment through education and embedded as active citizen-scientists changes the power and thus policy-making dynamics within communities (Freire 1968).

The first two elements combine to facilitate the third, policy change driven by residents with local governments (Mathews 2019) who are empowered and mobilized through data and awareness. Policy change occurs through multiple pathways, such as those described in Kingdon's multiple streams framework (1984). At the heart of the framework is the idea of a policy window; something has happened, a focusing event, that draws attention to a problem to be fixed or opportunity to be leveraged. Coronavirus and the pandemic are focusing events, but so too can be prolonged heightened measures of air pollution. Once residents are equipped with the data, knowledge of how to use the data, and awareness of the health consequences of poor air quality, new solutions can be pushed through the window. Empowerment of the citizenry is critical for the window to open and remain opened, particularly if poor air quality is localized and not likely to catch the attention of a wide dispersion of residents. Policy change that occurs to enhance air quality at any given period of time can save lives in the event of a significant health risk, such a coronavirus, in the future.

The AQED approach further allows for proactive, community-driven policy change, which is more likely to lead to sustainable and just environmental outcomes for historically underserved communities. Reactive policy changes might mitigate harms, but they fail to empower residents and policymakers to design spaces and systems that prevent environmental hazards from emerging at all (Agyeman 2005).

\section{Sensor networks as backbone of AQEDs}

Understanding the status of current air quality is crucial for air quality management. Currently, concentrations of important pollutants including $\mathrm{PM}_{2.5}$ are measured at stationary monitor networks using designated instruments that usually cost tens of thousands US dollars, and are expensive to operate and maintain (Hall et al. 2014). Due to the cost restrictions, the number of stations is limited, though pollution concentrations are known to vary drastically spatially (Karner et al. 2010).

The emerging low-cost air quality sensor is enabling a paradigm shift in the field of air quality monitoring (Snyder et al. 2013; Jiao et al. 2016). These sensors are generally easy to use, require minimum maintenance, and can provide data in near real-time. Due to their low cost, these sensors can be quickly deployed to establish a smart and connected network to characterize spatiotemporally resolved pollutant concentrations (Yi et al. 2015; Jiao et al. 2016). As a relatively new and still fast-evolving technology, the performances of low-cost air sensors vary considerably among models and are also impacted by environmental conditions such as temperature and humidity (Duvall et al. 2016). An active area of research is to develop methods for correcting sensor data, which we are currently working on using innovative modeling methods for remote calibration of sensors to improve sensor reliability (Miskell et al. 2019; Zheng et al. 2019).

Despite these shortcomings, the easy-to-use and lowmaintenance features of low-cost sensors enable genuine public participation in air quality monitoring, where affected or concerned communities and stakeholders can be involved throughout the entire process, such as monitor location selection, deployment, data collection and dissemination (English et al. 2017). Such a community-engaged and stakeholderinvolved approach not only addresses the needs of the general public related to air quality, but it also provides new avenues for public education, advances citizen science, and contributes to sustainable social development (Conrad and Hilchey 2011; Riesch and Potter 2014). However, areas that pursue AQEDs will need to consider how to cover the costs of the network, and best methods of education on sensor network use for the community.

As commercial air quality sensors have become more available, the US EPA has developed new tools and information to help air quality managers and the public better understand how they work and how to use them. There is also an interest in using air quality sensors to measure pollutant concentrations in localized areas with known air quality issues, or help identify where federal air quality monitors might be needed. The US EPA and other local air quality management agencies, such as the California Air Resources Board, are currently using sensors for exploratory research and supplemental monitoring (U.S. EPA 2020; CARB 2020).

\section{Parallel structures}

The AQED model has historical and contemporary parallels. First is the Air Quality Management District (AQMD), or Air Quality Compliance District. These are instituted to ensure local air quality is in alignment with federal standards and 
are used throughout the USA. The AQMD approach is expertbased and does not include a natural driver to empower residents who can meaningfully engage in dialogue and advocacy to enhance air quality, including and beyond the point of compliance. Second, there are a number of community air monitoring systems using low-cost sensors, mostly located in California, that have received strong support from the State of California's Air Resources Board (CARB 2020) that more closely resemble our approach. While each of these in California and elsewhere vary to some degree on the level of community involvement, community collaboration is a key feature of the network. However, we suggest a program with stronger federal support and funding to protect the long-term sustainability of these projects, especially as state and local areas grapple with serious budget shortfalls due to the COVID19 crisis.

\section{Conclusion}

Air quality enhancement districts with low-cost air quality sensors can provide important information for citizens to make better health-based decisions during and after the COVID-19 pandemic, especially in environmental justice communities. Since COVID-19 has been linked to higher mortality rates and causes permanent lung damage in some survivors, local air quality will be increasingly important in communities hardest hit by COVID19. These urban, poor, or underrepresented communities tend to have higher levels of air pollution and exposure due to industry, traffic, wildfires, construction, or other sources that may not be well measured by our existing federal air quality monitoring network. Using more highly distributed and accessible air quality sensors in an equitably designed AQED will empower citizens and communities to make better health-based decisions to mitigate further damage from COVID-19.

Funding This work is funded by the National Science Foundation award \#1931871, titled CPS: Medium: A Secure, Trustworthy, and Reliable Air Quality Monitoring System for Smart and Connected Communities. Along with the authors of this article, Dr. Xinwen Fu (University of Massachusetts Lowell) and Dr. Deliang Fan (Arizona State University) are Co-Investigators on this funded project.

\section{Declarations}

Conflict of interest The authors declare no competing interests.

\section{References}

Agyeman J (2005) Sustainable communities and challenges of environmental justice. New York University Press, New York

Bryer TA, Prysmakova-Rivera S (2018) Poor participation: fighting the wars on poverty and impoverished citizenship. Lexington Books, Lanham
Burnett R, Chen H, Szyszkowicz M, Fann N, Hubbell B, Pope CA, Apte JS, Brauer M, Cohen A, Weichenthal S, Coggins J (2018) Global estimates of mortality associated with long-term exposure to outdoor fine particulate matter. PNAS 115(38):9592-9597. https://doi.org/ 10.1073/pnas. 1803222115

California Air Resources Board (CARB) (2020) Community Air Protection Program. https://ww2.arb.ca.gov/capp/about. Accessed 20 May 2020.

Comunian S, Dongo D, Milani C, Palestini P (2020) Air pollution and Covid-19: the role of particulate matter in the spread and increase of Covid-19's morbidity and mortality. Int J Environ Res Public Health 17(12):4487

Conrad CC, Hilchey KG (2011) A review of citizen science and community-based environmental monitoring: issues and opportunities. Environ. Monit. Assess. 176(1-4):273-291. https://doi.org/10. 1007/s10661-010-1582-5

Conticini E, Frediani B, Caro D (2020) Can atmospheric pollution be considered a co-factor in extremely high level of SARS-CoV-2 lethality in Northern Italy? Environ. Pollut. 261:114465. https://doi. org/10.1016/j.envpol.2020.114465

Cox D (2020) Some patients who survive COVID-19 may suffer lasting lung damage. ScienceNews. https://www.sciencenews.org/article/ coronavirus-covid-19-some-patients-may-suffer-lasting-lungdamage.

Cui Y, Zhang ZF, Froines J, Zhao J, Wang H, Yu SZ, Detels R (2003) Air pollution and case fatality of SARS in the People's Republic of China: an ecologic study. Environmental Health 2(1):15

Duvall RM, Long RW, Beaver MR, Kronmiller KG, Wheeler ML, Szykman JJ (2016) Performance evaluation and community application of low-cost sensors for ozone and nitrogen dioxide. Sensors 16(10):1698. https://doi.org/10.3390/s16101698

English PB, Olmedo L, Bejarano E, Lugo H, Murillo E, Seto E, Wong M, King G, Wilkie A, Meltzer D, Carvlin G (2017) The Imperial County Community Air Monitoring Network: a model for community-based environmental monitoring for public health action. Environ Health Perspect 125(7):074501. https://doi.org/10. 1289/EHP1772

Fattorini D, Regoli F (2020) Role of the chronic air pollution levels in the Covid-19 outbreak risk in Italy. Environ. Pollut. 264:114732. https://doi.org/10.1016/j.envpol.2020.114732

Freedman A, Tierney L (2020) The silver lining to coronavirus lockdowns: air quality is improving. Washington Post. https://www. washingtonpost.com/weather/2020/04/09/air-quality-improvingcoronavirus/

Freire P (1968) Pedagogy of the Oppressed. Trans. Myra Berman Ramos. Herder, New York

Hall ES, Kaushik SM, Vanderpool RW, Duvall RM, Beaver MR, Long RW, Solomon PA (2014) Integrating sensor monitoring technology into the current air pollution regulatory support paradigm: practical considerations. Am J Environ Eng 4(6):147-154. https://doi.org/10. 5923/j.ajee.20140406.02

Heikkinen N (2018) To kill climate rule, Trump's EPA wants to redefine danger of soot. E\&E News. https://www.sciencemag.org/news/ 2018/08/kill-climate-rule-trump-s-epa-wants-redefine-danger-soot

Holmes L, Enwere M, Williams J, Ogundele B, Chavan P, Piccoli T, Okundaye O (2020) Black-White risk differentials in COVID-19 (SARS-COV2) transmission, mortality and case fatality in the United States: translational epidemiologic perspective and challenges. Int J Environ Res Public Health 17(12):4322. https://doi. org/10.3390/ijerph17124322

Jiao W, Hagler G, Williams R, Sharpe R, Brown R, Garver D, Judge R, Caudill M, Rickard R, Davis M (2016) Community Air Sensor Network (CAIRSENSE) project: evaluation of low-cost sensor performance in a suburban environment in the southeastern United States. Atmos Meas Tech 9(11):5281-5292. https://doi.org/10. 5194/amt-9-5281-2016 
Karner AA, Eisinger DS, Niemeier DA (2010) Near-roadway air quality: synthesizing the findings from real-world data. Environ Sci Technol. 44(14):5334-5344. https://doi.org/10.1021/es100008x

Kingdon JW (1984) Agendas, alternatives, and public policies. Little, Brown, Boston

Liu Y, Ning Z, Chen Y, Guo M, Liu Y, Kumar Gali N, Sun L, Duan Y, Cai J, Westerdahl D, Liu X, Xu K, Ho K, Kan H, Fu Q, Lan K (2020) Aerodynamic analysis of SARS-CoV-2 in two Wuhan hospitals. Nature. 582:557-560. https://doi.org/10.1038/s41586-0202271-3

Lodovici M, Bigagli E (2011) Oxidative stress and air pollution exposure. J. Toxicol. 2011:1-9. https://doi.org/10.1155/2011/487074

Mathews D (2019) With the people: making democracy work as it should. Dayton, The Kettering Foundation

Mehmood K, Saifullah IM, Abrar MM (2020) Can exposure to $\mathrm{PM}_{2.5}$ particles increase the incidence of coronavirus disease 2019 (COVID-19)? Sci. Total Environ. 741:140441-140441. https://doi. org/10.1016/j.scitotenv.2020.140441

Miranda ML, Edwards SE, Keating MH, Paul CJ (2011) Making the environmental justice grade: the relative burden of air pollution exposure in the United States. Int J Environ Res Public Health 8(6): $1755-1771$

Miskell G, Alberti K, Feenstra B, Henshaw GS, Papapostolou V, Patel H, Polidori Salmond JA, Weissert L, Williams DE (2019) Reliable data from low cost ozone sensors in a hierarchical network. Atmospheric Environ. 214:116870. https://doi.org/10.1016/j.atmosenv.2019. 116870

New York State Department of Health (NYSDH) (2020) COVID-19 Tracker. https://covid19tracker.health.ny.gov/views/NYSCOVID19-Tracker/NYSDOHCOVID-19Tracker-Map?\% 3 Aembed $=$ yes $\& \% 3$ Atoolbar $=$ no $\& \% 3$ Atabs $=$ n. Accessed 20 October 2020.

Park M, Joo HS, Lee K, Jang M, Kim SD, Kim I, Borlaza LJS, Lim H, Shin H, Chung KH, Choi YH (2018) Differential toxicities of fine particulate matters from various sources. Sci. Rep. 8(1):1-11. https://doi.org/10.1038/s41598-018-35398-0

Parker S (2016) CASAC Members Urge EPA to Broaden Scope of Next PM NAAQS Review. Inside EPA's Clean Air Report 27(11):10. https://doi.org/10.2307/48537403

Popovich N, Albeck-Ripka L, Pierre-Louis K (2019) 95 Environmental Rules Being Rolled Back Under Trump. The New York Times. https://www.nytimes.com/interactive/2019/climate/trumpenvironment-rollbacks.html.

Reilly S (2020) Trump's soot proposal bucks advice of EPA career staff. E\&E News. https://www.eenews.net/stories/1062872411.

Riesch H, Potter C (2014) Citizen science as seen by scientists: Methodological, epistemological and ethical dimensions. Public Underst Sci 23(1):107-120. https://doi.org/10.1177/ 0963662513497324

Santich K (2020) Coronavirus killing blacks in Florida's larger cities disproportionately. Orlando Sentinel. https://www.orlandosentinel. com/coronavirus/os-ne-coranavirus-florida-growing-racial-divide- in-covid-19-deaths-20200410-cyhgrfkkujg5jbbipttdi2bxcm-story. html.

Snyder EG, Watkins TH, Solomon PA, Thomas ED, Williams RD, Hagler GS, Shelow D, Hindin DA, Kilaru VJ, Preuss PW (2013) The changing paradigm of air pollution monitoring. Environ Sci Technol. 47(20):11369-11377. https://doi.org/10.1021/es4022602

United States Centers for Disease Control and Prevention (U.S. CDC) (2020). Scientific Brief: SARS-CoV-2 and Potential Airborne Transmission. https://www.cdc.gov/coronavirus/2019-ncov/more/ scientific-brief-sars-cov-2.html. Accessed 20 October 2020.

United States Environmental Protection Agency (U.S. EPA) (2019). Our Nation's Air. https://gispub.epa.gov/air/trendsreport/2019. Accessed 20 May 2020.

United States Environmental Protection Agency (U.S. EPA) (2020). AirNow. https://www.airnow.gov/aqi/aqi-basics/. Accessed 20 May 2020.

Wang B, Eum KD, Kazemiparkouhi F, Li C, Manjourides J, Pavlu V, Suh H (2020) The impact of long-term PM2.5 exposure on specific cause of death: exposure-response curves and effect modification among 53 million U.S. Medicare beneficiaries. Environ. Health 19(20). https://doi.org/10.1186/s12940-020-00575-0

Wolfe J (2020) African Americans more likely to die from coronavirus illness, early data shows. Reuters. https://www.reuters.com/article/ us-health-coronavirus-usa-race/african-americans-more-likely-todie-from-coronavirus-illness-early-data-shows-idUSKBN21O2B6.

Wu X, Nethery RC, Sabath BM, Braun D, Dominici F (2020) Exposure to air pollution and COVID19 mortality in the United States: a nationwide cross sectional study. medRxiv 2020.04.05.20054502. https://doi.org/10.1101/2020.04.05.20054502 Preprint

Yao Y, Pan J, Wang W, Liu Z, Kan H, Qiu Y, Wang W (2020) Association of particulate matter pollution and case fatality rate of COVID-19 in 49 Chinese cities. Sci Total Environ. 741:140396. https://doi.org/10.1016/j.scitotenv.2020.140396

Yi WY, Lo KM, Mak T, Leung KS, Leung Y, Meng ML (2015) A survey of wireless sensor network based air pollution monitoring systems. Sensors 15(12):31392-31427. https://doi.org/10.3390/s151229859

Zheng T, Bergin MH, Sutaria R, Tripathi SN, Caldow R, Carlson DE (2019) Gaussian process regression model for dynamically calibrating and surveilling a wireless low-cost particulate matter sensor network in Delhi. Atmos Meas Tech 12(9):5161-5181. https://doi. org/10.5194/amt-12-5161-2019

Zhu Y, Xie J, Huang F, Cao L (2020) Association between short-term exposure to air pollution and COVID-19 infection: evidence from China. Sci. Total Environ. 727:138704. https://doi.org/10.1016/j. scitotenv.2020.138704

Zoran MA, Savastru RS, Savastru DM, Tautan MN (2020) Assessing the relationship between surface levels of PM2.5 and PM10 particulate matter impact on COVID-19 in Milan, Italy. Sci Total Environ 738: 139825. https://doi.org/10.1016/j.scitotenv.2020.139825

Publisher's note Springer Nature remains neutral with regard to jurisdictional claims in published maps and institutional affiliations. 